\title{
Response to Commentaries on "Misidentified Flying Objects?"
}

Stuart W. Twemlow, M.D.

Topeka Institute for Psychoanalysis

University of Kansas School of Medicine, Wichita

ABSTRACT: In this response to the commentaries on my paper, "Misidentified Flying Objects?", I elaborate a middle ground position regarding the question of what is "really real." Using reports of near-death and UFO abduction experiences, I explicate further an integrated psychodynamic view of reality. This position proposes that at heart, reality is a dialectic between physicalness and nonphysicalness and that any attempt to "resolve". that dialectic is not only logically in error, but also pragmatically valueless.

I am very pleased and honored to have so much agreement with my ideas from as scholarly and erudite a group as those who responded to my paper, "Misidentified Flying Objects?" I certainly hope that these discussions lead not only to future research that furthers our knowledge of these interesting phenomena, but also to practical findings to assist individuals in their psychological adjustment to these experiences. For the sake of brevity, I will address here only the points of disagreement.

\section{Response to Keith Basterfield}

Keith Basterfield argued for another position in which the phenomena "might exist in an in-between state; they might become more

Stuart W. Twemlow, M.D., is in the private practice of psychiatry and psychoanalysis and serves on the Faculty of the Topeka Institute for Psychoanalysis, Menninger Foundation, Topeka, KS, and as Clinical Professor of Psychiatry at the University of Kansas School of Medicine, Wichita, KS. He is also Chief Instructor at the School of Martial and Meditative Arts in Topeka, KS, and Vice-President of the United States Kempo Federation. Reprint requests should be addressed to Dr. Twemlow at 5040 S.W. 28th Street, Topeka, KS 66614 . 
physical and other times more subjective" after the suggestion of the paranormal researcher Jenny Randles. In fact I think Basterfield has captured in this suggestion what the integrated psychodynamic perspective is at heart. Actually my paper was really about what is reasonable evidence for a middle-ground view of reality.

It might be useful to summarize an additional perspective from cognitive/perceptual psychology and from other psychoanalytic workers that allows us to see how an integrated psychodynamic perspective integrates a purely physical and purely psychological position. The hypothesis is that physicalness and nonphysicalness result from the way in which data are perceived by the human brain. My paper glossed over, perhaps too quickly, the seminal work of Michael Polanyi (1959) on his idea of the tacit dimension. Let me summarize another way of seeing how this view, the integrated psychodynamic perspective, is not reductionistic nor for that matter a way of avoiding the point, but is actually the only position that we can currently take with regard to establishing what is "really real," whether that applies to near-death experiences (NDEs) or unidentified flying object (UFO) abduction phenomena, or, for that matter, establishment of the very fact that the Journal of Near-Death Studies you are now reading is indeed real.

Roger Shepard, famous for his extraordinary pen drawings that are perceptual illusions, made a comment germane to this point:

Our perceptual experience of a stable, continuous, and enduring three-dimensional surrounding retains no trace of the prodigiously complex neuronal machinery that so swiftly constructs that experience. Nor are we aware of the shifting intermittent pointillistic, upside-down, curved, two-dimensional patterns of retinal excitation from which the machinery of the brain constructs our visual world. (1990, p. 4)

What has to happen then is that, first, the brain has to construct a multi-dimensional world from a two-dimensional retinal image-no mean task; and a task, of course, that involves references to prior knowledge from memory banks and to approximations and perceptual tricks to give a whole that is understandable to the mind. Shepard and others who work with perceptual illusion have clearly shown that the mind, in its various manipulations of perceptual and sensory data, frequently tends to fill in missing pieces from knowledge of prior experience and/or from inferences made from logical laws.

Second, the mind will tend to perceive the sensation mistakenly. Third, it may create artificial connections where none are present. And 
fourth, it may create specious stability in an image or phenomenon that is not there, so as to enable us to think in a stable, integrated way. For example, the way the brain filters much of reality, such as the spin of the earth, to permit stable images, is not, of course, perceived. If it was, it would create chaos in our lives.

Charles Tart (1992) stated that we live in a "neurologically based world simulator." That is, we do not directly experience the world outside our own heads. What we experience is an electrochemical pattern within our brain that is only a partially accurate simulation of the outside world. "And that simulation," he went on to say (p. 92), "is also based on on-going input, our cultural/personal biases, predispositions, and psychopathology, and our state of consciousness." Thus we live in a virtual reality.

F. Scott Fitzgerald (1956) once wrote: "The test of a first-rate intelligence is the ability to hold two opposed ideas in the mind at the same time, and still retain the ability to function." It is very difficult for Westerners to do this, since we are always trying to resolve paradoxes, perhaps a response to Cartesianism and to our assumption that knowledge will solve problems. The Orientals are much more comfortable with paradox, as is imbedded in their philosophy. I believe, however, that there is a Western philosophical structure that allows us to deal more creatively with the constant paradox of the subject/object dichotomy. Modern quantum mechanics allows us to demonstrate that a multiple set of realities is a possible adequate solution that does not require any either/or decision nor a single solution.

The Western concept of dialectic created by Georg Hegel is a process in which two opposing concepts create, inform, and preserve each other, while standing in a dynamic, everchanging relationship with each other. The dialectic process moves toward integration, but integration is never complete. Each attempt at integration creates "a new dialectical opposition and a new dynamic tension; of course in psychology the conscious/unconscious mind are two such dialectics. They are in mathematical terms empty sets being only full in relation to one another" (Ogden, 1986, p. 208). A subjective state is only relevant if an objective state exists, and vice versa; it is the dialectic that is real, not the individual components of it. Perhaps this idea can help explicate, in more Western language, this complex philosophical concept, and at the same time answer Basterfield's questions about whether or not this model truly spans the varying states of reality that seem to be possible.

Another point that Basterfield made, along with David Gotlib, is his comment on how this perspective explains the presence of physical phenomena accompanying the UFO abduction experience, including 
scars, damage to the environment, and possibly even brain implants. Since this question implies an "objective world" out there, I believe it will always remain unanswered: as Andre Gide wrote, the answer is the disease of the question.

Some phenomenologists talk about phenomenological reduction, that is, the bracketing off from the world of all projections and interpretations, implying that a substance will remain akin to noumena in the Kantian sense. This view implies that there is a "thing as it is," a reality so to speak, shorn of symbolic and imaginary projections. The integrated psychodynamic perspective does not deny the possibility of a physical world, but merely points out the co-equal importance of the subjective world. In other words, physical phenomena are meaningless in and of themselves, and are not to be taken as mere facts but to be interpreted as psychologically constructed variable consensual myths.

The extraordinary influence of the mind on the inanimate world is well documented in psychokinesis, the evidence for which is by no means minimal. In addition, it has been known for a long time that hypnotic suggestion can cause a variety of physical phenomena and sensations, including such extraordinary phenomena as the production of blisters on suggestion of the application of a hot stimulus to the skin. I quote these examples merely to illustrate the pervasiveness of mind, or alternatively that mind and matter are not practically or, for that matter, philosophically, separate.

Operating as a dialectic, physical phenomena such as UFO abduction experiences are no different, in my opinion, from what we call subjective or psychological phenomena. I very much appreciate the erudite questions Basterfield raised in his commentary. In part they have helped me ask the question of what the purpose of these varying perspectives is. I hope that a new scientific paradigm will emerge from these researches that will enable the complexities created by the subjectification of the objective, such as in the integrated psychodynamic perspective, to be explored more creatively.

\section{Response to David Gotlib}

Besides Gotlib's questions about the physical effects seen during UFO abduction phenomena, which I have already addressed, I would like to thank him for his useful comments on the difficulty of understanding psychodynamic constructs. I share his admiration for Kenneth Ring's imaginal realm writings. I believe there are many sim- 
ilarities between Ring's imaginal and my psychodynamic realms, as I will address in my comments on Ring's remarks below.

Gotlib was correct in stating that clinically the psychodynamic approach is sometimes pathologizing and can be misunderstood as dismissing phenomena not only as primarily mental, but as deceptive lies and hysterical constructions. This is unfortunate but understandable in light of the fact that the psychodynamic position is derived from the study of the workings of the disturbed mind. To that extent it has a more biased historical context than Ring's imaginal realm.

Gotlib correctly pointed out that the experience of otherness appears to be necessary for many of us, especially in the Western world. In my own studies of Zen and the martial arts, I have been impressed that there is still a big percentage of the world's population who do not necessarily need a Cartesian dualism to survive. In fact, all of the teachings of Zen do not deny the existence of duality but point out that the fundamental state of the universe is one of unity, and that failure to perceive this means that the individual lives his or her life with only half of the available information. I believe, as Gotlib implied, that recognition of the awesomeness of the human psyche as the constructor of the universe would be very much enhanced if individuals were able to see the fundamental nondualistic nature of their universe. But this is a whole other issue.

I have taken up Gotlib's challenge to apply these ideas to the process of therapy itself. I have elsewhere (1993) tried to explicate a hypothesis that I will outline here to promote further discussion, and that addresses Gotlib's criticism. In several decades of experience as a psychoanalyst and psychotherapist, and particularly in my teaching and supervision of therapists, I have been impressed with how the therapist's mind often operates very naively when considered from a perceptual/cognitive point of view.

When we talk about training therapists, we speak primarily of specific technique. Psychoanalysis added the dimension that the therapist needs to deal with his or her own neurosis, by recommending analysis or psychotherapy for therapists. Both efforts, the training in technique and the freeing of the therapist from distorting mental illness, are laudable ideas, but do not go far enough. Some of the ideas inherent in my model and in Ring's model should also be part of the preparation of the therapist.

I have taken some of the fundamental precepts of Zen and counterpointed them with a form of cognitive/perceptual training that allows the therapist to deploy attention in a way so that varying states of 
consciousness can be created, enabling a more accurate understanding of how state-dependent knowledge is (Twemlow, 1993). In that paper I also described a therapeutically useful series of basic innate presuppositions that we make about the world, such as the transience and emptiness of phenomena.

\section{Response to Fowler Jones}

Fowler Jones raised some most interesting questions about the psychological scales used to assess the mental health or perceptual cognitive characteristics of NDErs and UFO abductees. Fantasy-proneness is an interesting psychological construct derived from studies of hypnosis, creativity, and the mechanisms of concentration. There are a variety of scales available for measuring constructs such as this. I agree with Jones when he decried correlating high fantasy-proneness with either lying, malingering, or mental illness. It did not surprise me, nor did I think of it in a pejorative way, that UFO abductees may be high on measures of fantasy-proneness, because phenomena such as UFO abductions require a capacity to shift states of consciousness and demonstrate a high degree of flexibility of cognitive and perceptual mechanisms. Fantasy-proneness implies an openness to imagining in Ring's sense.

Stever Lynn and Judith Rhue (1986) showed a high correlation between fantasy proneness and Auke Tellegan's Absorption Scale (Tellegan and Atkinson, 1974). Jones and I used Tellegan's Absorption Scale in a study we conducted with Glen Gabbard of out-of-body experiencers (Twemlow, Gabbard, and Jones, 1982); NDErs tended to have significantly higher absorption scores compared to out-of-body experiencers (Gabbard and Twemlow, 1984). Tellegan's Absorption Scale does contain references to childhood fantasy (e.g., "Sometimes I feel and experience things as I did when I was a child"), but it focuses more particularly on a concept that in Oriental philosophy is called mushin, the capacity for deep levels of concentration without awareness of one's self as an entity separate from the experience. Thus the Absorption Scale also contains a great number of questions such as "I can be greatly moved by eloquent or poetic language," and "Different colors have distinctive and special meanings for me."

Jones went on to make an interesting observation about how one collects evidence that supports consensuality. He disagreed with my criticism of David Jacobs' idea that similarity of reports implies validation. Jones wrote that "the warp and woof of the abduction reports are 
not the total product of the defense systems"; but he would have to agree that all such reports are the product of the human brain. My point here is that there is no evidence to suppose that human minds work fundamentally differently in different cultures, even though they may have different contents. The neurotransmitters, the neuronal structure, and the functional mechanisms of the brain of an Eskimo and that of a highly sophisticated research scientist are not fundamentally different.

It does not surprise me that data of a shocking nature like UFO abduction experiences are interpreted similarly across subjects and even across cultures. Whatever the agreement or disagreement about the veridicality of the reports, it is agreed that the vast majority are shocking and thus a UFO abduction is a highly stressful experience. Jones correctly pointed out that UFO sightings have been reported throughout human history, but I am not sure that UFO abductions have been. Abductions certainly do not seem to have been reported as frequently in the past as they have been recently, although of course we can never really know about prevalence and incidence from the study of historical literature. This will have to be a prospective study for future generations of workers.

With regard to Jones's question about the most therapeutic attitude for the therapist when dealing with an abductee, my experience has been that while therapists may be able to maintain a neutral position with regard to such experiences for a while, patients will usually insist on some sort of position statement. I have found it helpful to say something like the following:

I believe that you have had an experience as you describe it, and I do not believe that you are lying or malingering. I consider it to be wholeheartedly true that such an experience has occurred to you. My specific personal beliefs do not seem particularly important, although I am completely open-minded on this topic.

Later Jones returned to the matter of Michael Sabom's research on NDErs who observed idiosyncratic aspects of their experiences that would be hard to explain unless they had somehow been observing their open-heart surgery. Part of the problem with such forms of argument is that whether something is in or out of the brain is usually the central feature. I believe that this may be a specious argument, a disease of the question.

I already recognized the evidence for the presence of certain paranormal phenomena. A widened view of human psychology might include 
the fairly well established possibility of telepathic, clairvoyant, and psychokinetic functioning of the human psyche. It is not at all improbable that observations that seem to be "out of the body" are simply paranormal forms of functioning of the human mind. Contrary to Jones's objection, it seems quite possible that normal defenses, which are not to be confused with psychopathology, could enable the individual to perceive or create such realities as part of the overall mechanism of psychic adaptation.

\section{Response to Alvin Lawson}

Alvin Lawson's vigorously argued proposition that NDEs and UFO abductions are recreations of birth trauma memories is an intriguing one. Historically such hypotheses date from the work of Otto Rank (1929), one of Sigmund Freud's early students, who was also an expert on mythology and anthropology. Freud briefly embraced and incorporated some of Rank's ideas on recalled birth trauma into his own theories, but later became disillusioned with them, reasoning that a baby with no verbal skills or capacity to structure the world of everyday reality could not possibly process the highly structured memories often connected with birth trauma recall.

A sophisticated reworking of these ideas by another psychoanalyst, Stanislav Grof (1975), and a subsequent elaborate psychology derived from these ideas led to a repopularization and a reprinting of Rank's classic work, The Trauma of Birth (1929). Grof convincingly divided the birth process into a series of stages involving reactions to compression of the fetal head and resultant anoxia. In work initially using lysergic acid diethylamide (LSD) and other psychedelic substances, and later a "holotropic breathing technique," Grof collected an immense amount of data across subjects that seemed to provide a phenomenological typology consistent with his hypothesis.

I worked with and was a student of Grof in the early days and participated with him in using LSD to treat various forms of psychopathology. I was quite impressed with the data being produced, especially its intense and dramatic qualities and the interesting connection not only with birth trauma but with the mythology and folktales of many cultures. Unlike a number of individuals, I do not have difficulty with whether or not the infant is sufficiently organized to remember such complex experiences.

I do not, of course, expect to find verbally structured memories using a consistent frame of reference and clearly connected with knowledge 
that could only have been learned after symbolization and verbal grasp had occurred. There is no reason, however, to suppose that the mind of a child remains a tabula rasa. It likely does remember some kinds of things, especially physiological experiences; and subsequently various associative images could well be connected in an attempt to provide a thinkable structure for these complex early physiological "memories."

The first application of such ideas to near-death experiences was by Carl Sagan (1979): borrowing from Grof's work he made a direct analogy between NDEs and birth trauma. Later his work was elegantly refuted by Carl Becker (1982). Although Becker may have adopted an extreme position, he did point to some issues that seem valid to me. For example, in a near-death experience, passage through the vaginal canal would hardly be tunnel-like from the newborn's point of view, the heroic figure of light is unlikely to be a loving Godlike figure, nor can panoramic memories be explained by such analogies. Birth trauma is largely unpleasant and NDEs are largely pleasant, although UFO abductions are not.

A middle ground certainly seems possible. The criticism of oversimplification could be applied to neurophysiological models such as those of Ronald Siegel (1980), which draw an analogy between aspects of the NDE and a variety of neurophysiological events. As Gabbard and I commented in our analysis of such models:

One would be hard pressed to question that the perception of the NDE imagery must be mediated through central nervous system structures and neurophysiological processes. All mental function is. As explanatory models designed to understand a causation of the NDE, however, these hypotheses are sorely reductionistic. First of all, Siegel makes a fundamental error in assuming that because certain perceived phenomena are similar, they can be presumed to have the same underlying cause. Phenomenological similarities abound in nature, without adherence to unicausality. (Gabbard and Twemlow, 1984, p. 131)

This fundamental error of logic in Siegel's model is common as well in the UFO abduction field, such as in the theories of Jacobs and possibly even Lawson, in his rather dogmatic, reductionistic assertion of a birth trauma hypothesis. Although I am by no means unsympathetic to Lawson's ideas, they need to be tested in a prospective study involving an attempted correlation between varieties of NDEs and UFO abductions on the one hand and type of birth on the other. For example, events such as a Caesarian section or forms of obstructed labor may have correlations within the imagery itself. 
Turning now to Lawson's discussion of fantasy-proneness and UFO abductees, as I have already discussed, I do not believe the capacity for absorption, fantasy, or image production is necessarily connected with fabrication, deception, or a tendency for naive "acceptance." In my experience in working with patients, highly hypnotizable individuals who are fantasy-prone and high on absorption are not necessarily naive and gullible and are quite capable of distinguishing trance from nontrance states.

The intriguing argument that unimaginative abductees utilize these experiences to revitalize their lives is original if not eccentric, and again needs empirical testing. Psychopathology among NDErs and UFO abductees needs to be explored. In my own studies of NDErs and out-of-body experiencers, I found no preponderance of abnormal psychopathology (Gabbard and Twemlow, 1984; Twemlow, Gabbard, and Jones, 1982). On the other hand, it certainly is very likely that psychopathological individuals have such experiences. Individuals with severe psychopathology often fantasize very little, contrary to the widely accepted myth. Those with severe borderline and psychotic pathology are often frightened of fantasizing, overwhelmed by their own hallucinations, and their capacity for imagination is very severely restricted by virtue of the terrifying pathology. Is it possible then that these unimaginative abductees have severe psychopathology?

With regard to whether or not such experiences are positive or negative, Lawson made a good point. In my own studies, both out-ofbody and near-death experiences were described by subjects as predominantly positive, although about 5 percent considered them predominantly negative. I believe in fact that even experiences full of love and light, such as some of the classical near-death accounts, are unlikely to be experienced without a tinge of fear. Even the numinous has an aweinspiring, rather frightening aspect, although it could be described as largely positive.

\section{Response to Kenneth Ring}

I thoroughly appreciate Kenneth Ring's elegant pleas for an imaginal approach to these interesting phenomena. In fact I believe that, as I understand his approach, there are no fundamental differences with my propositions except that, as he pointed out, the psychodynamic approach is derived from the understanding of pathological mental states, and the imaginal is not. Although there is a problem with the 
language of ego psychology, including terms such as "defense" and "resistance," I believe there are far less pathologizing, more modern relational paradigms, such as object relations theories, that emphasize the incorporation and identification of images of relationships and the essential object-seeking nature of human behavior. I use the term psychodynamic in this more modern sense. Much of the modern understanding of psychodynamics evolved from developmental studies of normal and pathological infants.

With these general comments in mind, I would like to respond to some more specific issues Ring raised. I believe that the possibility of a distinctive encounter-prone psychological profile for experiencers is an intriguing idea. As I noted above, although my studies have shown no evident psychopathology, I did find NDErs to have higher scores on Tellegan's Absorption Scale and out-of-body experiencers to have more UFO sightings than a control group.

I might speculate that the so-called encounter-prone personality may be one aspect of a much broader mental set capable of a variety of forms of cognition and perception categorized as paranormal. In a previous work (Twemlow, Hendren, Gabbard, Jones, and Norris, 1982), I hypothesized that such individuals call upon psychic forms of ego functioning when struggling to survive. This very dangerous century and our uncertain future might well call for the emergence of a more encounter-prone personality. I would prefer a less specific phrase, like the psychedelic (expanded mind) personality.

Ring correctly chided me for emphasizing negative outcomes of UFO abduction experiences. Of course, people that I see clinically have had negative outcomes; that's why they visit a therapist. I am certainly open to the idea that both NDEs and UFO abduction experiences have a personal transforming effect. As a matter of fact, I have noticed that with adequate psychotherapy, major losses, even psychotic illness, and especially major trauma, including serious illnesses like cancer, can have a life-transforming effect. As Ring pointed out, such experiences open up possibilities. I found this with my out-of-body subjects: even though the out-of-body experience in most of these subjects was quite mundane phenomenologically, its impact on the individual was to open up a broader horizon of possibilities. Major trauma of any sort often jolts the individual into an increased awareness of the world and of the present moment. I agree with Ring that modern abduction research has an unfortunate paranoid tone to it. Further research, like Ring's excellent explorations, does help remedy this unbalanced state of affairs. 


\section{References}

Becker, C.B. (1982). The failure of Saganomics: Why birth models cannot explain neardeath phenomena. Anabiosis: The Journal of Near-Death Studies, 2, $102-109$.

Fitzgerald, F.S. (1956). The crack-up. (E. Wilson, Ed.). New York, NY: New Directions. (Original work published 1936)

Gabbard, G.O., and Twemlow, S.W. (1984). With the eyes of the mind. An empirical analysis of out-of-body states. New York, NY: Praeger.

Grof, S. (1975). Realms of the human unconsciousness. New York, NY: Viking.

Lynn, S.J., and Rhue, J.W. (1986). The fantasy-prone person: Hypnosis, imagination, and creativity. Journal of Personality and Social Psychology, 51, 404-408.

Ogden, T.H. (1986). The matrix of the mind. Northvale, NJ: Jason Aronson.

Polanyi, M. (1959). The study of man. Chicago, IL: University of Chicago Press.

Rank, O. (1929). The trauma of birth. New York, NY: Harcourt, Brace.

Sagan, C. (1979). Broca's brain: Reflections on the romance of science. New York, NY: Random House.

Shepard, R.N. (1990). Mindsights. New York, NY: Freeman.

Siegel, R. (1980). The psychology of life after death. American Psychologist, 25, 911-931.

Tart, C.T. (1992). Perspectives on scientism, religion, and philosophy provided by parapsychology. Journal of Humanistic Psychology, 32, 70-100.

Tellegan, A., and Atkinson, G. (1974). Openness to absorbing and self-altering experiences ("absorption"): A trait related to hypnotic susceptibility. Journal of Abnormal Psychology, 53, 268-277.

Twemlow, S.W. (1993). The Zen of the therapist: A proposal for a new integrated focus in the training of a psychotherapist. Paper presented at the Menninger Foundation Conference, Heart of Healing: A Conference on Transpersonal Psychology, Topeka, KS, March 12.

Twemlow, S.W., Gabbard, G.O., and Jones, F.C. (1982). The out-of-body experience: A phenomenological typology based on questionnaire responses. American Journal of Psychiatry, 139, 450-455.

Twemlow, S.W., Hendren, R.L., Gabbard, G.O., Jones, F.C., and Norris, P.A. (1982). Egointegrating function of psi states. Journal of Psychiatric Treatment and Evaluation, 4, 41-49. 